\title{
Computational Aspects of Electromagnetic Fields near H.V. Transmission Lines
}

\author{
Ossama E. GOUDA ${ }^{1}$, Ghada M. AMER ${ }^{2}$, Waleed A. SALEM ${ }^{\mathbf{2}}$ \\ ${ }^{1}$ the Engineering College, Cairo University, Cairo, Egypt \\ ${ }^{2}$ the High Institute of Technology, Benha University, Benha, Egypt \\ Email:prof_ossama11@yahoo.com, \{dr_ghada,eng_waleed269\}@benha-univ.edu.eg
}

\begin{abstract}
Biological effects of electromagnetic fields on the human body, animals and plants have been a subject of scientific interest and public concern for their risk on the living organisms such as blood leukemia and others. The high voltage transmission and distribution lines, which pass beside some houses, factories and schools are source of electromagnetic fields. This paper presents the field calculations around and near of high voltage transmission lines $220 \mathrm{kV}$ and $500 \mathrm{kV}$. To calculate the induced current, the power density, the electric field and the magnetic field of grounded and ungrounded human body cylindrical model are used. MATLAB program package is used for mathematical calculation of the distribution of the EMF in human body under high voltage power transmission lines.
\end{abstract}

Keywords: computational aspects, EMF, H. V., transmission lines

\section{Introduction}

Electric and magnetic fields produced by electric power systems have recently been added to the list of environmental agents that are a potential threat to public health $[1$, 2]. The increasing use of distribution and transmission of electrical energy between randomly occurring causes concerns regarding the risks of human exposure to nearfield radiation from the transmission lines and electric substations. The studies into the health effects of longterm exposure have been progressing on several fronts [1]. At ground level, beneath high-voltage transmission lines, the electric fields created have the same frequencies as those carried by the power lines. The characteristics of these fields depend on the line voltage, and on the geometrical dimensions and positions of the conductors of the transmission line. [1] Inside buildings near HV transmission lines, the field strengths are typically lower than the unperturbed field by a factor of about 10-100, depending on the structure of the building and the type of materials [1]. The magnetic field beneath high-voltage overhead transmission lines is directed mainly transversely to the line axis. In this paper calculations are carried out for the electromagnetic fields near the overhead transmission lines and also the induced current produces in human body due to these fields.

\section{Computational Model for EMF under H.V. Transmission Line Calculation}

In this paper the electric field $\mathrm{E}$, induced in the human body when exposed to a transmission power line electric field $E^{\text {inc }}$, is determined in analytical form using the surface integral equation method. Account is taken of the presence of the earth below the three-phase Power line [3]. Model of long-distance power line consists of threephase power lines which are arranged in several different configurations that are used in this study. The central conductor number 1 is in the plane $y=0$, while conductors number 2 and number 3 are respectively in the planes $\mathrm{y}=\mathrm{L}$ and $\mathrm{y}=-\mathrm{L}$. Three conductors in the plane $\mathrm{z}=\mathrm{d}$ in the air (Region 0 ) above the surface $\mathrm{z}=0$ of the earth (Region 1) are shown in Figure 1. The electromagnetic fields near $220 \mathrm{kV}$ and $500 \mathrm{kV}$ high voltage tower are calculated in three dimensions by using (1) to (6). The analytical formulas for the field calculations of the three phase's power system are derived in [4] Final Stage

$$
\begin{aligned}
E_{0 x}(0, y, z)= & \frac{i \omega \mu_{0} l}{\pi k_{1}^{2}}\left(k_{0} d\right)\left\{\frac{(z+d)^{2}-y^{2}}{\left[(z+d)^{2}+y^{2}\right]^{2}}+e^{\frac{i 2 \pi}{3}}\left[\frac{(z+d)^{2}-(y+L) 2}{\left[(z+d)^{2}+(y+L)^{2}\right]^{2}}\right]\right. \\
& \left.+e^{-\frac{i 2 \pi}{3}}\left[\frac{(z+d)^{2}-(y-L) 2}{\left[(z+d)^{2}+(y-L)^{2}\right]^{2}}\right]\right\}
\end{aligned}
$$




$$
\begin{aligned}
& E_{0 y}(0, y, z)=\frac{i \omega \mu_{0} l}{2 \pi k_{0}}\left\{y\left[\frac{1}{(z-d)^{2}+y^{2}}-\frac{1-\frac{2 k_{0}^{2}}{k_{1}^{2}}}{(z+d)^{2}+y^{2}}\right]+e^{\frac{i 2 \pi}{3}}(y+L)\left[\frac{1}{(z-d)^{2}+(y+L)^{2}}-\frac{1-\frac{2 k_{0}^{2}}{k_{1}^{2}}}{(z+d)^{2}+(y+L)^{2}}\right]\right. \\
& \left.+e^{-\frac{i 2 \pi}{3}}(y-L)\left[\frac{1}{(z-d)^{2}+(y-L)^{2}}-\frac{1-\frac{2 k_{0}^{2}}{k_{1}^{2}}}{(z+d)^{2}+(y-L)^{2}}\right]\right\} \\
& E_{0 z}(0, y, z)=\frac{\omega \mu_{0} l}{2 \pi k_{0}}\left\{\frac{z-d}{(z-d)^{2}+y^{2}}-\frac{z+d}{(z+d)^{2}+y^{2}}+e^{i 2 \pi / 3}\left[\frac{z-d}{(z-d)^{2}+(y+L)^{2}}-\frac{z+d}{(z+d)^{2}+(y+L)^{2}}\right]\right. \\
& \left.+e^{-i 2 \pi / 3}\left[\frac{z-d}{(z-d)^{2}+(y-L)^{2}}-\frac{z+d}{(z+d)^{2}+(y-L)^{2}}\right]\right\} \\
& B_{0 x}(0, y, z)=-\frac{2 i \mu_{0} l k_{0}}{\pi k_{1}^{2}}\left\{\frac{y(z+d)}{\left[(z+d)^{2}+y^{2}\right]^{2}}+e^{i 2 \pi / 3} \frac{(y+L)(z+d)}{\left[(z+d)^{2}+(y+L)^{2}\right]^{2}}+e^{-i 2 \pi / 3} \frac{(y-L)(z+d)}{\left[(z+d)^{2}+(y-L)^{2}\right]^{2}}\right\} \\
& B_{0 y}(0, y, z)=\frac{\mu_{0} l}{2 \pi}\left\{\frac{4(z+d)\left(k_{0} d\right)}{k_{1}^{2}\left[(z+d)^{2}+y^{2}\right]^{2}}\left[1-\frac{2\left[(z+d)^{2}-y^{2}\right]}{(z+d)^{2}+y^{2}}\right]-\frac{z-d}{(z-d)^{2}+y^{2}}+\frac{z+d}{(z+d)^{2}+y^{2}}+e^{i 2 \pi / 3}\left(\frac{4(z+d)\left(k_{0} d\right)}{k_{1}^{2}\left[(z+d)^{2}+(y+L)^{2}\right]^{2}}\right.\right. \\
& \left.\left[1-\frac{2\left[(z+d)^{2}-(y+L)^{2}\right]}{(z+d)^{2}+(y+L)^{2}}\right]-\frac{z-d}{(z-d)^{2}+(y+L)^{2}}+\frac{z+d}{(z+d)^{2}+(y+L)^{2}}\right)+e^{-i 2 \pi / 3}\left(\frac{4(z+d)\left(k_{0} d\right)}{k_{1}^{2}\left[(z+d)^{2}+(y-L)^{2}\right]^{2}}\right. \\
& \left.\left.\left[1-\frac{2\left[(z+d)^{2}-(y-L)^{2}\right]}{(z+d)^{2}+(y-L)^{2}}\right]-\frac{z-d}{(z-d)^{2}+(y-L)^{2}}+\frac{z+d}{(z+d)^{2}+(y-L)^{2}}\right)\right\} \\
& B_{0 z}(0, y, z)=\frac{\mu_{0} l}{2 \pi}\left\{\frac{y}{(z-d)^{2}+y^{2}}-\frac{y\left(1-2 k_{0}^{2} / k_{1}^{2}\right)}{(z+d)^{2}+y^{2}}+\frac{4 y\left(k_{0} d\right)}{k_{1}^{2}\left[(z+d)^{2}+y^{2}\right]^{2}}\left[1+\frac{2\left[(z+d)^{2}-y^{2}\right]}{(z+d)^{2}+y^{2}}\right]+e^{i 2 \pi / 3}\left(\frac{(y+L)}{(z-d)^{2}+(y+L)^{2}}\right.\right. \\
& \left.-\frac{(y+L)\left(1-2 k_{0}^{2} / k_{1}^{2}\right)}{(z+d)^{2}+(y+L)^{2}}+\frac{4(y+L)\left(k_{0} d\right)}{k_{1}^{2}\left[(z+d)^{2}+(y+L)^{2}\right]^{2}}\left[1+\frac{2\left[(z+d)^{2}-(y+L)^{2}\right]}{(z+d)^{2}+(y+L)^{2}}\right]\right)+e^{-i 2 \pi / 3}\left(\frac{(y-L)}{(z-d)^{2}+(y-L)^{2}}\right. \\
& \left.\left.-\frac{(y-L)\left(1-2 k_{0}^{2} / k_{1}^{2}\right)}{(z+d)^{2}+(y-L)^{2}}+\frac{4(y-L)\left(k_{0} d\right)}{k_{1}^{2}\left[(z+d)^{2}+(y-L)^{2}\right]^{2}} \times\left[1+\frac{2\left[(z+d)^{2}-(y-L)^{2}\right]}{(z+d)^{2}+(y-L)^{2}}\right]\right)\right\} \\
& \underset{\text { Region } 0 \text { (air) }}{:}
\end{aligned}
$$

Figure 1. Tower of power line simulation, conductors at height " $d$ " over earth (flat configuration) 
where $\mathrm{E}_{0 \mathrm{x}}(0, \mathrm{y}, \mathrm{z}), \mathrm{E}_{0 \mathrm{y}}(0, \mathrm{y}, \mathrm{z})$, and $\mathrm{E}_{0 \mathrm{z}}(0, \mathrm{y}, \mathrm{z})$ are electric field components of the three phases in $\mathrm{x}, \mathrm{y}$ and $\mathrm{z}$ planes respectively. $\mathrm{B}_{0 \mathrm{x}}(0, \mathrm{y}, \mathrm{z}), \mathrm{B}_{0 \mathrm{y}}(0, \mathrm{y}, \mathrm{z})$, and $\mathrm{B}_{0 \mathrm{z}}(0, \mathrm{y}, \mathrm{z})$ are magnetic field components of the three phases in $\mathrm{x}, \mathrm{y}$ and $\mathrm{z}$ planes respectively. $\mathrm{L}$ is the distance between power line phases. $\mathrm{d}$ is the vertical distance from the earth to the power lines. I is the line current in ampere. $k_{0}$ is the wave number of the air and $k 1$ is the wave number of the earth and $\mu_{0}$ is the permeability of free space. The parameters for the transmission lines $220 \mathrm{kV}$ and $500 \mathrm{kV}$ are given in Table 1. The electromagnetic field for $220 \mathrm{kV}$ and 500 $\mathrm{kV}$ are shown in Figures 2 to 10 at distances 0, 2, 4, 6, 8, 10,12 , and 20 meters starting from the transmission lines conductors.

Table 1. the parameters for the transmission lines $220 \mathrm{kV}$ and $500 \mathrm{kV}$

\begin{tabular}{ccc}
\hline parameters & $\mathbf{2 2 0} \mathbf{~ k V}$ & $\mathbf{5 0 0} \mathbf{~ k V}$ \\
\hline $\mathbf{L}$ & $3 \mathrm{~m}$ & $12 \mathrm{~m}$ \\
$\mathbf{D}$ & $15 \mathrm{~m}$ & $19.1 \mathrm{~m}$ \\
$\mathbf{I}$ & $300 \mathrm{~A}$ & $1200 \mathrm{~A}$ \\
$\mathbf{F}$ (frequency) & $50 \mathrm{~Hz}$ & $50 \mathrm{~Hz}$ \\
$\mathbf{Z}$ & From 0 to $15 \mathrm{~m}$ & From 0 to $18 \mathrm{~m}$ \\
\hline
\end{tabular}

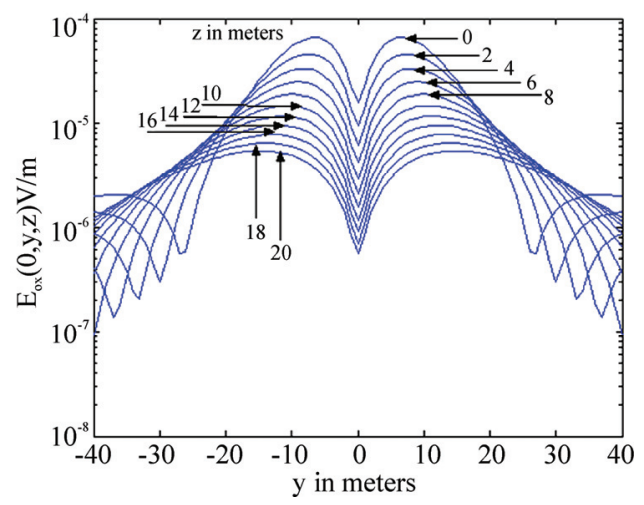

Figure 2. $\mathrm{E}_{0 \mathrm{x}}(0, \mathrm{y}, \mathrm{z})$ near a $220 \mathrm{kV}$ three-wire power line over vertical distance from 0 to $20 \mathrm{~m}$, current $=300 \mathrm{Amp}$

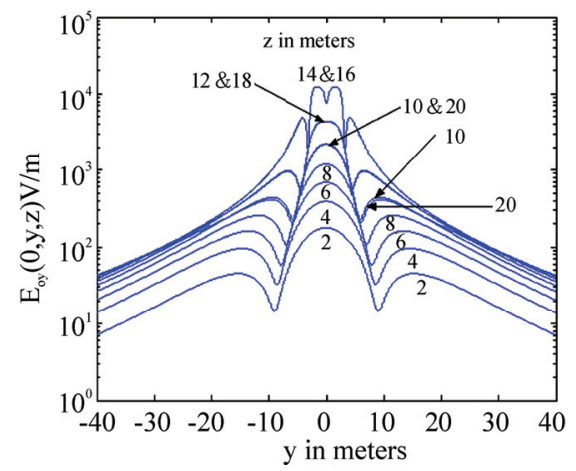

Figure 3. $\mathrm{E}_{0 \mathrm{y}}(0, \mathrm{y}, \mathrm{z})$ near a $220 \mathrm{kV}$ three-wire power line over vertical distance from 0 to $20 \mathrm{~m}$, current $=300 \mathrm{Amp}$

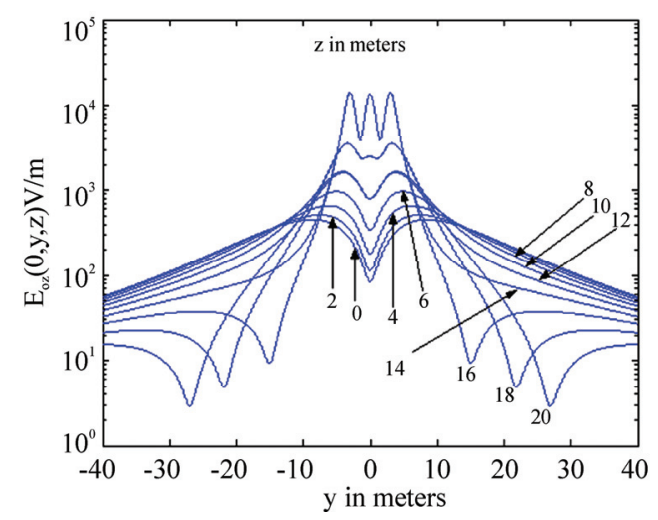

Figure 4. $E_{0 z}(0, y, z)$ near a $220 \mathrm{kV}$ three-wire power line over vertical distance from 0 to $20 \mathrm{~m}$, current $=300 \mathrm{Amp}$

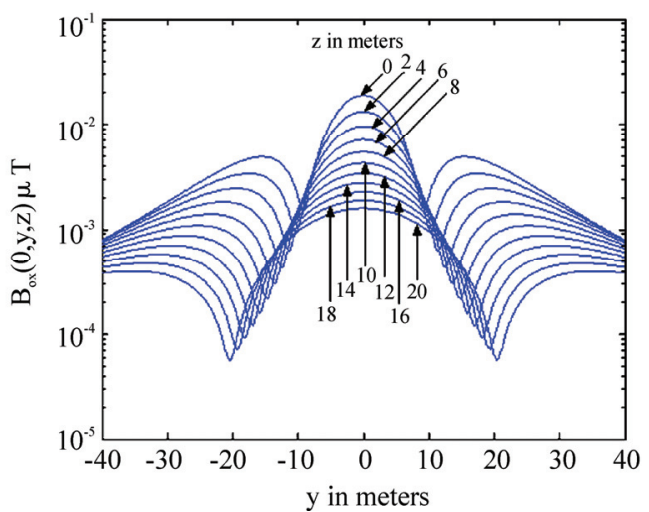

Figure 5. $\mathbf{B}_{0 \mathrm{x}}(0, \mathrm{y}, \mathrm{z})$ near a $220 \mathrm{kV}$ three-wire power line over vertical distance from 0 to $20 \mathrm{~m}$, current $=300 \mathrm{Amp}$

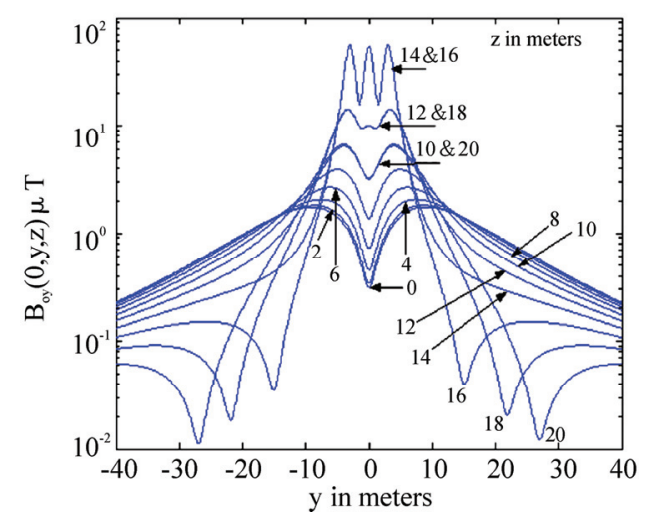

Figure 6. $B_{0 y}(0, y, z)$ near a $220 \mathrm{kV}$ three-wire power line over vertical distance from 0 to $20 \mathrm{~m}$, current $=300 \mathrm{Amp}$

\section{Computational Model for Induced Current in Human Body}

The human body is a complex structure with parts like skin, fat, bone, marrow, muscle, blood, nerve fibers, etc., each of which is characterized on the macroscopic level 
and within definite boundaries by a conductivity $\sigma$ and a relative permittivity $\varepsilon_{\mathrm{r}}$, that may be frequency dependent and anisotropic. The average conductivity $\sigma$ for most tissue types $0.5 \mathrm{~S} / \mathrm{m}$ is taken in calculation of electric field inside human body [5]. To study the induced current, the power density, the electric field and the magnetic field of grounded and ungrounded human body cylindrical model is represented by a cylinder as shown in Figure 11.

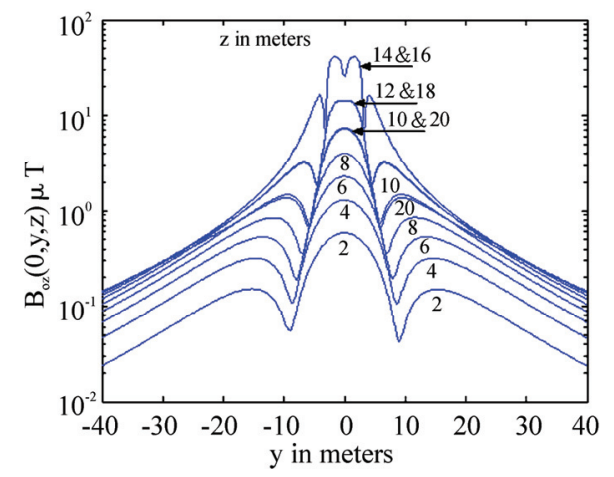

Figure 7. $B_{0 z}(0, y, z)$ near a $220 \mathrm{kV}$ power line over vertical distance from 0 to $18 \mathrm{~m}$, current $=300 \mathrm{Amp}$

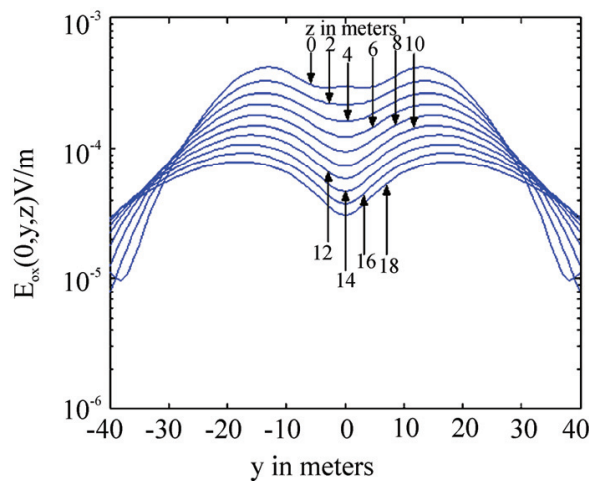

Figure 8. $\mathbf{E}_{0 \mathrm{x}}(0, \mathrm{y}, \mathrm{z})$ near a $500 \mathrm{kV}$ power line over vertical distance from 0 to $20 \mathrm{~m}$, current $=1200 \mathrm{Amp}$

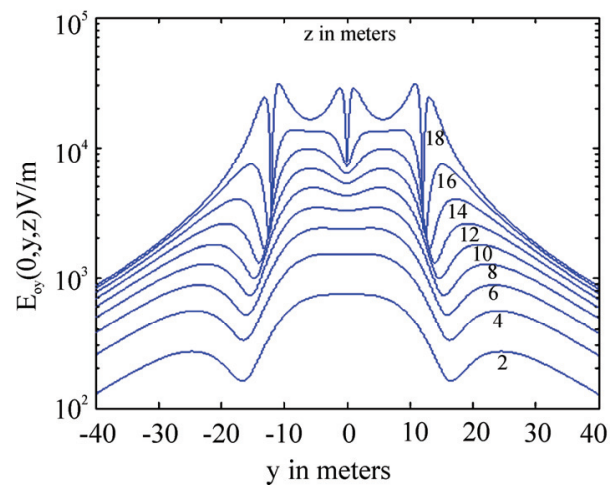

Figure 9. $\mathrm{E}_{0 \mathrm{y}}(0, \mathrm{y}, \mathrm{z})$ near a $500 \mathrm{kV}$ three-wire power line over vertical distance from 0 to $18 \mathrm{~m}$, current $=1200 \mathrm{Amp}$

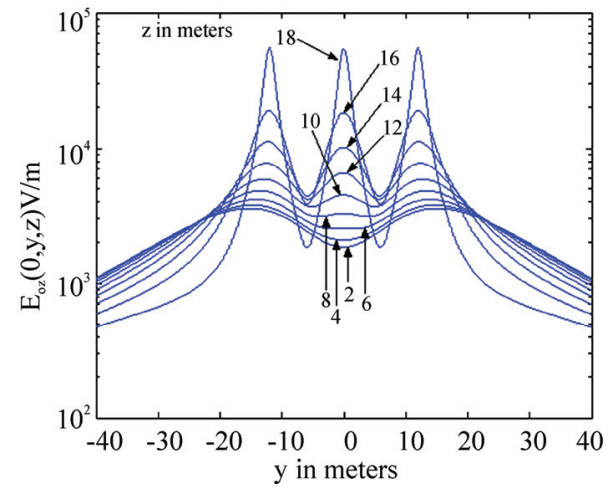

Figure $10 . \mathrm{E}_{0 \mathrm{z}}(0, \mathrm{y}, \mathrm{z})$ near a $500 \mathrm{kV}$ three-wire power line over vertical distance from 0 to $18 \mathrm{~m}$, current $=1200 \mathrm{Amp}$

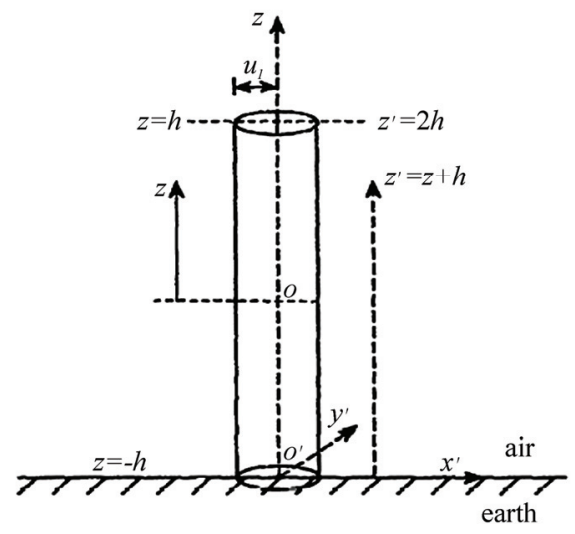

Figure 11. Coordinates $x^{\prime}, y^{\prime}, z$ with origin $O$ on axis at center of cylinder and $x^{\prime}, y^{\prime}$, $z^{\prime}$ with origin $O$ 'on axis at base (surface of earth); $z^{\prime}=z+h, h^{\prime}=\mathbf{2 h}$

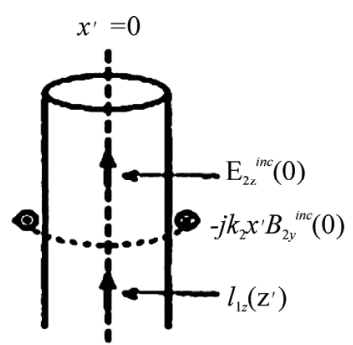

(a)

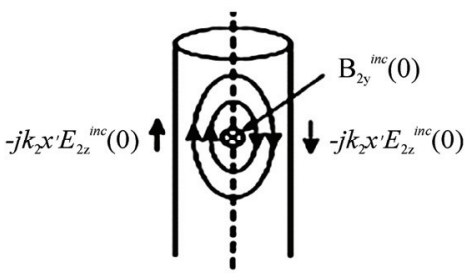

(b)

Figure 12. Induced current in a cylindrical conducting body (a) governed by an integral equation (b) governed by ampere's law 
The integral equation for the current induced in a cylindrical conducting body as shown in Figure 12 is readily evaluated when the body is electrically short, a) $\mathrm{E}_{2 \mathrm{z}}{ }^{\text {inc }}(0)$ and $\mathrm{B}_{2 \mathrm{y}}{ }^{\mathrm{inc}}(0)$ induce an axial current $\mathrm{I}_{1 \mathrm{z}}\left(\mathrm{z}^{\prime}\right)$ by using an integral equation, and $b$ ) $\mathrm{E}_{2 \mathrm{z}}{ }^{\text {inc }}(0)$ and $\mathrm{B}_{2 \mathrm{y}}{ }^{\text {inc }}(0)$ induce a circulating current governed by ampere's law. The circulating current of electric field induced in the cylindrical body by $\mathrm{B}_{2 \mathrm{y}}{ }^{\text {inc }}$ component is smaller than that induced by $\mathrm{E}_{2 \mathrm{z}}^{\text {inc }}$ and it can be ignored.

When a person is under or near a power line not too close to the earth, such as lying in a bed in an upstairs bedroom near a power line, or a lineman in an elevated basket works under one of the wires, the body acts as an isolated electrically very short parasitic antenna excited by the component of the electric field parallel to its length. Since the body is a good conductor at $\mathrm{f}=50 \mathrm{~Hz}$ and is long compared with its cross sectional dimensions, the well-known integral equation for the total axial current induced in a conducting cylinder by the field $\mathrm{E}_{\mathrm{s}}$ inc can be applied. Here $E_{s}$ inc is the part of the axial field that is constant in amplitude over any transverse cross section of the body. With a body length $2 \mathrm{~h}=1.75 \mathrm{~m}$ and a mean radius $\mathrm{a}_{1}=0.14 \mathrm{~m}$, the electrical half-length at $\mathrm{f}=50 \mathrm{~Hz}$ is $\mathrm{k}_{\mathrm{o}}=9.16 \mathrm{X} \mathrm{lo}^{-7}<<1$, where $\mathrm{k}_{\mathrm{o}}$ is the wave number of the air. The current induced in a parasitic antenna parallel to an s-directed electric field is [6-10].

$$
I_{s}(s)=\frac{j 4 \pi E_{s}^{i n c}}{k_{0} \zeta_{0}} \frac{\cos k_{0} s-\cos k_{0} h}{\psi_{d U} \cos k_{0} h-\psi_{U}(h)}
$$

where:

$\mathrm{S}=0$ is the center of the body.

$\mathrm{s}= \pm \mathrm{h}$ are its two ends of the body.

$\mathrm{k}_{\mathrm{o}}$ is the wave number of the air, $\mathrm{k}_{\mathrm{o}}=\omega / \mathrm{c}=2 \pi \mathrm{f} / \mathrm{c}$ and $\mathrm{c}$ is the velocity of the light.

$\zeta_{0}=\left(\mu_{0} / \varepsilon_{0}\right)^{1 / 2}, \mu_{0}$ is permeability of free space and $\varepsilon_{0}$ is permittivity of free space.

When $\mathrm{k}_{\mathrm{o}} \mathrm{h}<<1,(7)$ can be reduced to

$$
I_{s}(s)=\frac{j 2 \pi k_{0} h^{Z} E_{s}^{i n c}}{\zeta_{0} \psi_{d U}}\left(1-\frac{s^{Z}}{h^{Z}}\right)
$$

Note that the current at the center, $s=0$, is

$$
I_{s}(0)=\frac{j 2 \pi k_{0} h^{Z} E_{s}^{i n c}}{\zeta_{0} \psi_{d U}}
$$

where $\psi_{d U}=2 \ln \left(2 h / a_{1}\right)-3, k_{0} h<<1$

$$
E_{s}(s)=\frac{J_{s}(s)}{\sigma}=\frac{I_{s}(s)}{\sigma \pi a_{1}^{Z}}
$$

The heat generated in the body by $\mathrm{J}(\mathrm{s})$ is given by power density

$$
P(s)=\sigma\|E(s)\|^{2}
$$

the magnetic field in the body due to the axial current
$I(s, \rho)=\pi \rho^{2} J(s, \rho)$ is given by:

$2 \pi p \mu_{0}^{-1} B(\rho, s)=I_{s}(\rho, s)$ or $B(\rho, s)=0.5 \rho \mu_{0} J_{s}(s)$

The magnetic field equation can be written as

$$
B(\rho, s)=j \pi \rho E_{s}^{i n c}\left(1-\frac{s^{2}}{h^{2}}\right) \times 10^{-7}
$$

$\rho$ is the radius of the cylinder.

A man in good contact with the earth as shown in Figure 11 can be represented by a cylinder of radius $a_{1}$ has a collinear image in the earth. He may have insulated soles with a capacitive impedance $Z_{L}=-j / \omega C$ between them and their image, or he may be barefooted with $Z_{L}=0$. The current in the body in the general case is given by [6]

$$
\begin{gathered}
I_{Z}\left(Z^{\prime}\right)=\frac{j 2 \pi k_{0} h^{\prime z} E_{Z}^{i n c}}{\zeta_{0} \psi}\left(1-\frac{Z^{\prime 2}}{h^{\prime 2}}+\frac{Z_{L}}{Z_{L}+Z_{0}}\left(1-\frac{Z^{\prime}}{h^{\prime}}\right)\right) \\
0 \leq z^{\prime} \leq h^{\prime}=2 h
\end{gathered}
$$

where $z^{\prime}=z+h$ is measured upward from the surface of the earth and $h^{\prime}=2 h$ is the length of the body (half-length of the body and its image).

$$
Z_{0}=-\frac{j \varsigma_{0} \psi}{2 \pi k_{0} h_{m}^{\prime}}, \quad \psi=2 \ln \frac{2 h_{m}^{\prime}}{a_{m}}-3
$$

where $h_{m}^{\prime}$ is the distance from the top of the head at $z^{\prime}=h^{\prime}$ to the point of maximum current at $z^{\prime}=z_{m}^{\prime}$. $Z_{0}$ is the impedance of the body referred to the maximum of current at the distance $h_{m}^{\prime}$ from the top of the head. $z^{\prime}$ is the maximum height of human body. $z_{m}^{\prime}$ is the point at the maximum current and $\mathrm{a}_{\mathrm{m}}$ is the equivalent radius $\mathrm{a}_{\mathrm{m}}=$ $(A / \pi)^{0.5}$ where $A$ is the area of the cross section at $z_{m}^{\prime}$. The location of the maximum current is [3]

$$
Z_{m}^{\prime}=\frac{h^{\prime}}{2} \frac{Z_{L}}{Z_{0}+Z_{L}}
$$

So that

$$
h_{m}^{\prime}=h^{\prime}\left(1-\frac{1}{2} \frac{Z_{L}}{Z_{0}+Z_{L}}\right)
$$

When (13) is expressed in terms of $\mathrm{z}$ and $\mathrm{h}$, it becomes

$$
I_{Z}(Z)=\frac{j 2 \pi k_{0} h^{Z} E_{Z}^{i n c}}{\zeta_{0} \psi}\left(1-\frac{z^{Z}}{h^{Z}}+\frac{2 Z_{0}}{Z_{0}+Z_{L}}\left(1-\frac{z}{h}\right)\right)
$$

where $\mathrm{z}$ is measured upward from the center of the body and $h$ is its half-length. In (17)

$$
Z_{0}=-\frac{j \zeta_{0} \psi}{2 \pi k_{0} h_{m}}, \psi=2 \ln \frac{2 h_{m}}{a_{m}}-3
$$

where $h_{m}$ is the distance from the top of the head at $\mathrm{z}=\mathrm{h}$ to the point of maximum current at $\mathrm{z}=\mathrm{z}_{\mathrm{m}}$. Where

$$
Z_{\mathrm{m}}=-\frac{Z_{0} h}{Z_{0}+Z_{L}}, h_{m}=h\left(1+\frac{Z_{0}}{Z_{0}+Z_{L}}\right)
$$


Three cases of special interest are:

1) $Z_{L}=\infty$ this means that the person is far from the surface of the earth.

2) $Z_{L}=-j / \omega C$ this means that the person is standing on a paved road or sidewalk or directly on the earth with insulating soles, and

3) $Z_{L}=0$ this means that the person is barefooted in good contact with the earth.

The first case is given by (8) with $\mathrm{s}=\mathrm{z}$. the other two cases are considered as the following: The capacitance $\mathrm{C}$ between the soles of the feet and their image is approximately given by (20) and the impedance between the soles of the feet is given by (21). Where $A=0.06 \mathrm{~m}^{2}$ is the area of the soles, $\varepsilon_{\mathrm{r}}=2$ is the relative permittivity of the insulating layer of asphalt, cement or rubber and its image, $\varepsilon_{\mathrm{o}}=8.85 \times 10^{-12}$ and $\mathrm{d}$ is the thickness of the layer and its image [3].

$$
\begin{aligned}
& \mathrm{C}=\mathrm{A} \varepsilon_{\mathrm{r}} \varepsilon_{0} / \mathrm{d} \\
& \mathrm{Z}_{\mathrm{L}}=-\mathrm{j} / \omega \mathrm{C}
\end{aligned}
$$

The electric field, magnetic field, axial current in the human body model, power density, electric and magnetic field due to axial current are calculated for the three cases as:

1) The human is grounded then $Z_{L}=0$ this means that the person is barefooted in good contact with the earth. With $Z_{L}=0, h^{\prime}=1.75 \mathrm{~m}, \mathrm{k}_{0} \mathrm{~h}^{\prime}=2.2 \times 10^{-6}, \mathrm{~h}_{\mathrm{m}}^{\prime}=\mathrm{h}, \mathrm{a}_{\mathrm{m}}$ $=0.138, \psi=3.47$, and $Z_{0}=-j 0.79 \times 10^{8}$. From (13) takes the form:

$$
I_{Z}\left(z^{\prime}\right)=j 2.22 \times 10^{-8} E_{z}^{\text {inc }}\left(1-\frac{z^{\prime Z}}{h^{\prime Z}}\right), 0 \leq z^{\prime} \leq h^{\prime}
$$

2) The human is standing on a paved road or sidewalk or directly on the earth with insulating soles:-consider the first layer is consisting of $13 \mathrm{~cm}$ of asphalt and $1.5 \mathrm{~cm}$ of rubber, i.e. the thickness of the layer and its image of two layers is $\mathrm{d}=29 \mathrm{~cm}$, From $(20) \mathrm{C}=3.66 \times 10^{-12} \mathrm{~F}, \mathrm{Z}_{\mathrm{L}}=$ $-\mathrm{j} 8.69 \times 10^{8} \Omega$ is calculated using (21) where f equals 50 Hz. At $\mathrm{a}_{\mathrm{m}}=(\mathrm{A} / \pi)^{0.5}=(0.06 / \pi)^{0.5}=0.138$, for maximum current at $\mathrm{z}_{\mathrm{m}}=0.117 \mathrm{~m}$ then $\mathrm{h}_{\mathrm{m}}=0.992 \mathrm{~m}$. From (14) it is found that $Z_{0}=-j 9.34 \times 10^{7} \Omega$ is calculated. The axial current from (17) is calculated by the following equation:

$$
\begin{aligned}
& I_{Z}(z)=j 8.26 \times 10^{-9} E_{z}^{\text {inc }}\left(1-\frac{z^{Z}}{h^{Z}}+0.194\left(1-\frac{z}{h}\right)\right) \\
& h \leq z \leq h
\end{aligned}
$$

3) For a human stand directly on moist earth with rubber soles of $1 \mathrm{~cm}$ thick, $\mathrm{d}=2 \mathrm{~cm}, \mathrm{C}=53.1 \times 10^{-12} \mathrm{~F}, \mathrm{Z}_{\mathrm{L}}=$ $-\mathrm{j} 0.6 \times 10^{8} \Omega, \mathrm{Z}_{\mathrm{m}}^{\prime}=0.165 \mathrm{~h}^{\prime}=0.289 \mathrm{~m}, \mathrm{~h}^{\prime} \mathrm{m}=0.835 \mathrm{~h}^{\prime}=$ $1.461 \mathrm{~m}, \psi=3.11$ and $Z_{0}=-\mathrm{j} 0.847 \times 10^{8} \Omega$. The axial current is calculated as:

$$
I_{Z}\left(z^{\prime}\right)=j 2.47 \times 10^{-8} E_{Z}^{i n c}\left(1-\frac{z^{\prime Z}}{h^{\prime Z}}-0.415\left(1-\frac{z^{\prime}}{h^{\prime}}\right)\right)
$$

$$
0 \leq z^{\prime} \leq h^{\prime}
$$

The electric and magnetic fields, the total current, and power densities in the interior of a human body when the body is exposed to $10^{4} \mathrm{~V} / \mathrm{m}$ in the three cases are determined and graphed as shown in Figures 13 to 16 .

\section{Conclusions}

1) The electromagnetic field near a high voltage transmission line is determined in analytical form. Cylindrical model is used in calculating the electric and magnetic fields, the total axial current, and power densities in the interior of a human body are determined when the human is standing on the ground under or near the line .

2) Analytical method is used for calculating the interior currents and power densities of human body when the human body is grounded, isolated by soles and isolated in moist soil.

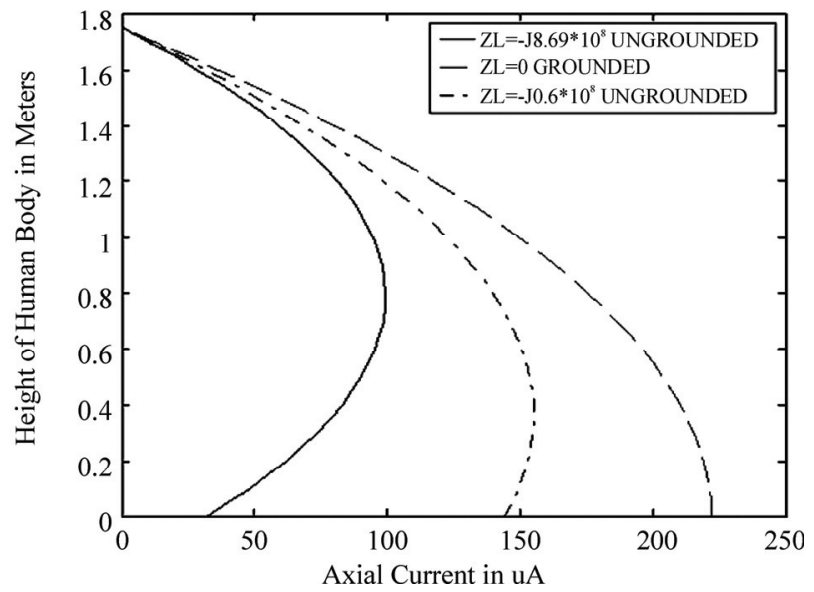

Figure 13. Total axial current in grounded and ungrounded human model; $\sigma=0.5 \mathrm{~S} / \mathrm{m}, \mathrm{E}_{\mathrm{z}}^{\text {inc }}=10^{4} \mathrm{~V} / \mathrm{m}$ and $\mathrm{f}=50 \mathrm{~Hz}$

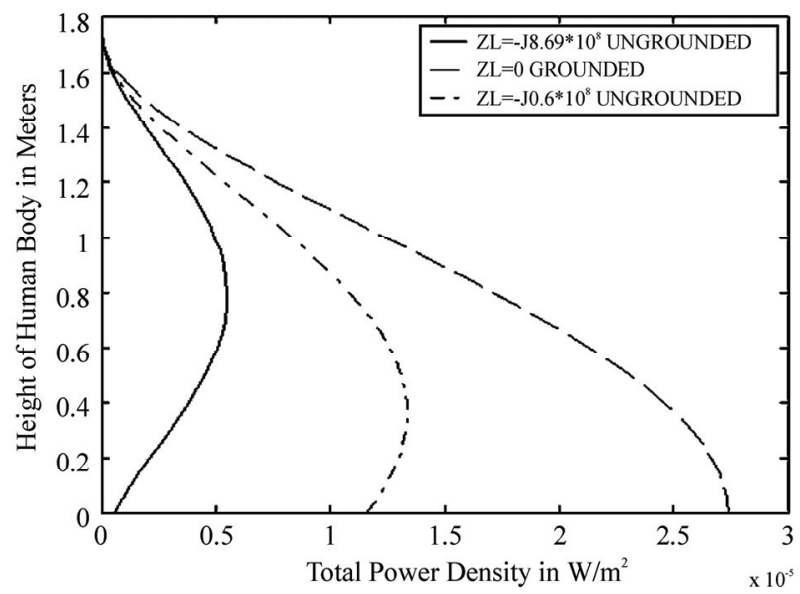

Figure 14. Total power density in grounded and ungrounded human model; $\sigma=0.5 \mathrm{~S} / \mathrm{m}, \mathrm{E}_{\mathrm{z}}^{\text {inc }}=10^{4} \mathrm{~V} / \mathrm{m}$ and $\mathrm{f}=50 \mathrm{~Hz}$ 


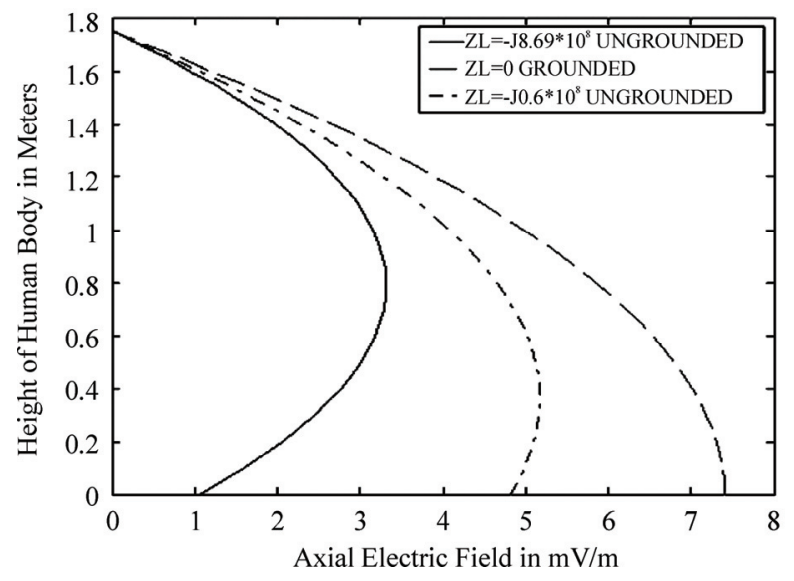

Figure 15. Total axial electric field in grounded and ungrounded human model; $\sigma=0.5 \mathrm{~S} / \mathrm{m}, E_{\mathrm{z}}^{\text {inc }}=10^{4} \mathrm{~V} / \mathrm{m}$ and $\mathrm{f}=50 \mathrm{~Hz}$

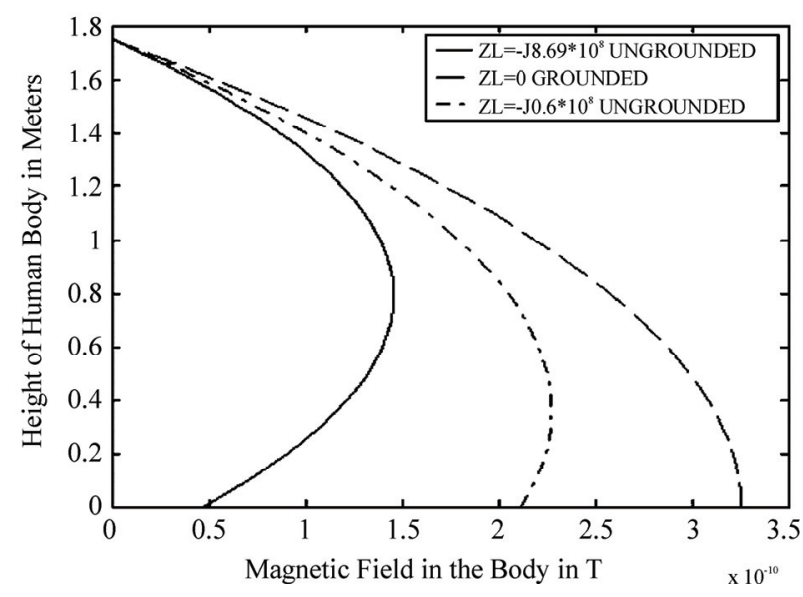

Figure 16. The magnetic field in the body due to axial current in grounded and ungrounded human model; $\rho=0.14 \mathrm{~m}$, $\sigma=0.5 \mathrm{~S} / \mathrm{m}, E_{\mathrm{z}}^{\text {inc }}=10^{4} \mathrm{~V} / \mathrm{m}$

\section{REFERENCES}

[1] A. H. E. Manders and N. S. Van Nielen, "The magnetic field surrounding high tension lines in the Netherlands and their influence on humans and animals," Elektrotechniek, Vol. 59, No. 7, 1981.

[2] R. Hauf, "Non-ionizing radiation protection," Copenhagen, World Health Organization Regional Office for Europe, WHO Regional Publications, European Series No. 10, 1982.

[3] R. W. P. Kinga and T. T. Wu, "The complete electromagnetic field of a three-phase transmission line over the earth and its interaction with the human body," Journal of Applied Physics, Vol. 78, No. 2, 1995.

[4] D. Margetis, "Electromagnetic fields in air of traveling-wave currents above the earth," Journal of mathematical physics, Vol. 39, No. 11, pp. 5870-5893, 1998.

[5] F. Barnes and B. Greenebaum, "Book of bioengineering and biophysical aspects of electromagnetic fields," 2006.

[6] J. Jin, "The finite element method in electromagnetics," Wiley, New York, 1993.

[7] D. M. Sullivan, D. T. Borup, and O. P. Gandhi, "Use of the finite-difference time-domain method in calculating EM absorption in human tissues," IEEE Transactions on Bioengineering, Vol. BME-34, pp. 148-157, February 1987.

[8] R. W. P. King, "Fields and currents in the organs of the human body when exposed to power lines and VLF transmitters," IEEE Transactions on Biomedical Engineering, Vol. 45, No. 4, pp. 520-530, April 1998.

[9] D. G. Wu, "Numerical analysis of interactions between fields and human bodies," Ph.D. Thesis, University of Houston, May 2006

[10] A. Barchanski, M. Clemenc, H. De Gersem, and T. Weiland, "Efficient calculation of current densities in the human body induced by arbitrarily shaped, low frequency magnetic field sources," Journal of Computational Physics, Vol. 214, pp. 81-95, 2006. 